\title{
The effect of brain lesions on prism-adaptation in monkey
}

\author{
Joseph Bossom I \\ NATIONAL INSTITUTE OF MENTAL HEALTH
}

\begin{abstract}
Systematic misreaching produced by placing ophthalmic prisms over the eyes becomes gradually diminished with prolonged exposure. The present experiment was designed to determine whether or not brain lesions which do not disrupt normal visuomotor coordination will retard the recovery of accurate reaching in prismwearing monkeys. Both frontal lobectomy and lesions of the caudate nucleus were found to have this effect.

\section{Problem}

Visuomotor adaptation to prisms occurs gradually even though $\mathrm{S}$ is not able to view either his apparently displaced arms or body and has no information about his prism-induced reaching errors. On the basis of behavioral analysis, it has been suggested that when the prisms are worn, $\mathrm{S}$ obtains the information necessary to modify his reaching by monitoring the unique changes in movement of the visual field which accompany his self-initiated head movements (Bossom, 1964). Several theories have been proposed to account for this type of prism-adaptation. Recovery of accurate reaching has been termed a visuomotor process (Held \& Bossom, 1961), a proprioceptive change (Harris, 1963), spatial orientation and motor learning. Other authors have referred to prism-adaptation as a perceptual process explicable on the basis of variables such as sensoritonic effects (Werner \& Wapner, 1955).

The present experiment was designed to determine whether or not brain lesions affect the recovery of reaching accuracy in prism-wearing monkeys. However, it was difficult to predict which lesions, if any, would impair the rate at which accurate reaching is recovered. If a perceptual process is involved, then lesions in striate or temporal cortex which have been shown to affect visual perception might also have an effect on prism-adaptation (Mishkin, in press). Similar results might be expected from occipito-parietal lesions because of their known effect on spatial orientation and visual space perception (Paterson \& Zangwell, 1944). Frontal cortex lesions might also be expected to have an effect because of their supposed involvement in visuomotor coordination (Bechterev, 1928; Teuber, 1964). The purpose of the present experiment was, therefore, to test the effect upon the recovery of reaching accuracy in prism-wearing monkeys of as many cortical and subcortical lesions as practicable. The experiment was designed to determine which lesions, if any, would impair the rate at which accurate reaching is recovered.

\section{Procedure}

Ss were 60 Macaca mulatta, 11 of whom were unoperated normal controls whose rate of prism-adaptation was used as a basis against
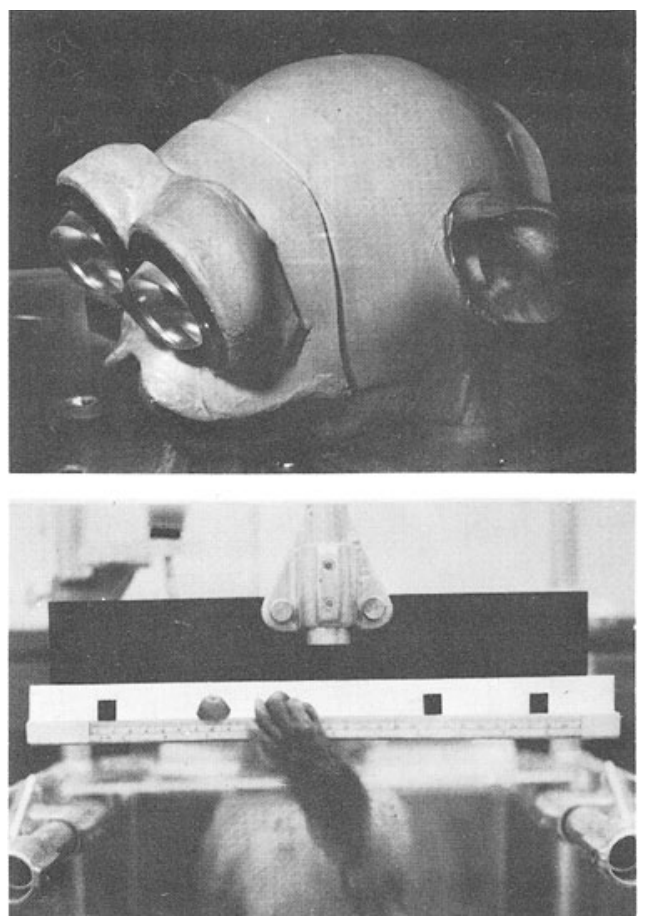

Fig. 1. Boundaries of bilateral cortical resections. Dotted line indicates the frontal lobectomy although the cortical resection was extended to sulcus principalis.

which the performance of the operated groups was compared. For 39 operated Ss a mean of 11 weeks elapsed between surgery and testing. For 10 other operated Ss more than 2 years had elapsed before testing.

The effect of 13 different bilateral cortical and subcortical lesions was studied. The boundaries of the cortical lesions, made by aspiration, are depicted in Fig. 1. These lesions and the $\mathrm{N}$ prepared with each were: frontal lobectomy, $\mathrm{N}=3$; $\mathrm{LF}$, lateral frontal, $\mathrm{N}=7$; $\mathrm{OF}$, orbital frontal, $\mathrm{N}=7$; $\mathrm{ST}$, superior temporal, $\mathrm{N}=3$; IT, inferotemporal, $\mathrm{N}=5$; $\mathrm{AMT}$, anterior medial temporal, $\mathrm{N}=3$; LS lateral striate, $\mathrm{N}=4$; $\mathrm{PS}$, prestriate $\mathrm{N}=3$ and $\mathrm{PP}$, postèrior parietal, $\mathrm{N}=3$. The bilateral subcortical lesions were made by RF thermocoagulation, They involved: a maximum of $64 \%$ to a minimum of $13 \%$ of the magnocellular part of medialis dorsalis destroyed in an $\mathrm{N}$ of $2 \mathrm{Ss}$; a maximum of $36 \%$ to a minimum of $14 \%$ of amygdala destroyed in an N of 2 Ss. A maximum of $31 \%$ to a minimum of $21 \%$ of hippocampus destroyed in an $\mathrm{N}$ of $2 \mathrm{Ss}$, and caudate nucleus lesions ranging from $41 \%$ maximum to $24 \%$ minimum in an $\mathrm{N}$ of $5 \mathrm{Ss}$. All brains were processed by histological techniques and the lesions verified. Sections and reconstructions are available for examination at N.I.H.

During the experiment Ss were maintained and tested in primate chairs which were modified to receive the presentation shelf used to test reaching accuracy. S could obtain a piece of food which had been placed on the far edge of this shelf by reaching forward, up and around a cm ruler as shown in Fig. 2. The distance between the point on the ruler intersected by the radial surface of S's hand and the location of the food-target was the measure of reaching error. Additional rewards were placed on the shelf out of S's view to insure 
that each response would be rewarded regardless of its accuracy. The underside of the testing shelf was made opaque so that $\mathrm{S}$ was prevented from seeing his arm in transit during the reaching tests. Twenty diopter opthalmic prisms (A.O. No. 1815) worn before S's eyes during the exposure period were held in place by a form-fitted helmet and provided an aligned binocular visual field subtending $60^{\circ}$ displaced laterally by $11.2^{\mathrm{O}}$ (Fig. 2).

The general procedure consisted of a test-exposure-retest sequence in which the direction to which $\mathrm{S}$ reached was measured before and after the prisms were placed over his eyes and before and after their removal following $7 \mathrm{hr}$. of exposure. Additional intra-exposure measurements were obtained at the $1 \mathrm{st}, 3 \mathrm{rd} \& 5$ th $\mathrm{hr}$. to determine the course of the error-correction. All trials were replicated with the prism base rotated $180^{\circ}$ to control for summative effects which have been found to occur in humans (Held \& Bossom, 1961).

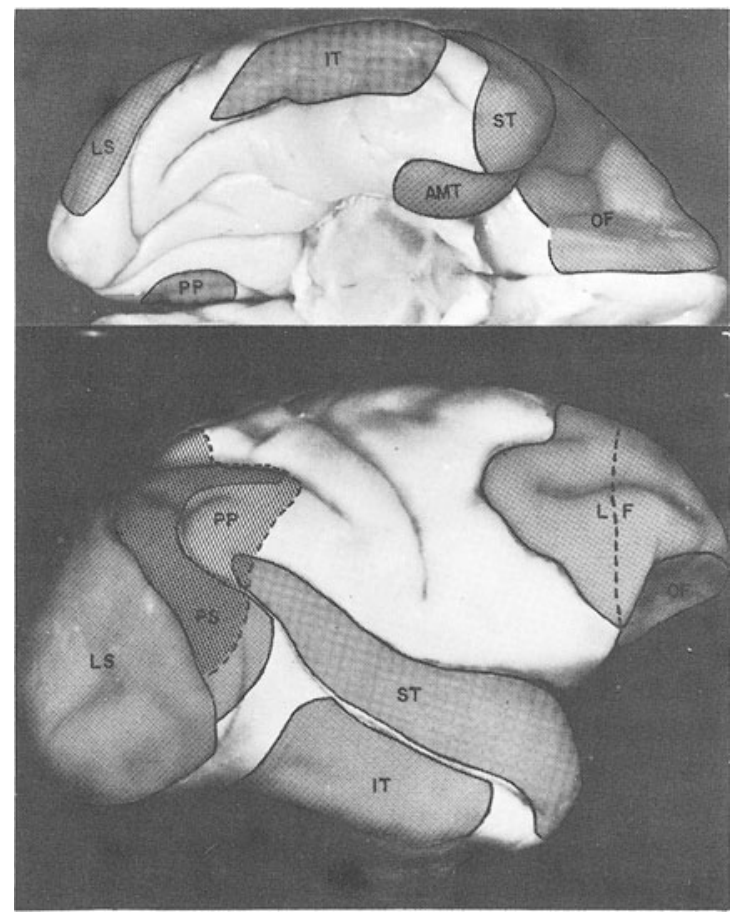

Fig. 2. (top) Binocular ophthalmic prisms held before S's eyes by a form-fitted helmet. (bottom) $S$ reaches accurately for a grape framed in one of the four apertures. Additional rewards are placed behind the barrier to insure that a reward will be obtained for misreaching.

\section{Results and Diseussion}

Adaptation was measured by determining the percent of prism-induced reaching error that was compensated for after $7 \mathrm{hr}$. of exposure. The overall difference between the normal and operated groups was significant $(p<.001)$. The caudate nucleus lesion group compensated for $30 \%$ of the induced error and the frontal lobectomy group $35 \%$. Neither of these values is significantly greater than zero. Using Dunnet's test only these two groups were found to have had significantly less than the $79 \%$ adaptation found in the normal group $(p<.05 \&$ $\mathrm{p}<.05)$ In neither of these groups was an increase in the variability of reaching observed, indicating that the effect is restricted to what has been termed visuomotor plasticity and does not involve a disruption of normal visuomotor coordination.

Although the present results are preliminary, they do suggest that the prefrontal cortex and the head of the caudate nucleus are at least part of the neural substrate which mediates prism-adaptation. It is not possible, however, to determine whether the caudate nucleus is involved in prism-adaptation because of its interrelationships with prefrontal cortex (Rosvold \& Szwarcbart, 1964) or, more directly, through its participation in the extra-pyramidal system. The present experiment was not designed to determine which of the various theories of prism-adaptation is most tenable. It is just as likely that, inasmuch as both structures have been implicated in what has been termed a perseverative deficit (Rosvold \& Szwarcbart, 1964), that such perseveration is acting here to maintain normal visuomotor coordinations and therefore retard prism-adaptation, or that these lesions interfere with the visuomotor feedback system described by Held \& Bossom (1961), among others, in which patterns of visual input are correlated with afference associated with motor outflow resulting in a re-matching of visual space with the movement sequences that comprise localization. Research now in progress is designed to clarify these alternatives.

\section{References}

BECHTEREV, V. M. General principals of human reflexology: An introduction to the objective study of personality. London: Jarrolds Publishers, 1928.

BOSSOM, J. Mechanisms of prism adaptation in normal monkeys. Psychon. Sci., 1964, 377-378.

HARRIS, C. S. Adaptation to displaced vision, visual motor or proprioceptive change. Science, 1963, 140, 812-813.

HELD, R., \& BOSSOM, J. Neonatal deprivation and adult rearrangement: Complementary techniques for analyzing plastic sensorimotor coordinations. J. comp. physiol. Psychol., 1961, 54, 33-47.

MISHKIN, M. Visual mechanisms beyond the striate cortex. In R. Russel (Ed.), Frontiers of physiological psychology. New York: Academic Press, in press.

PATTERSON, A., \& ZANGWELL, O. L. Disorders of visual space perception associated with lesions of the right cerebral hemisphere. Brain, 1944, 67, 331-358.

ROSVOLD, H. E., \& SZWARCBART, M. K. Neutral structures involved in delayed response performances. In J. M. Warren \& K. Akert (Eds.), The frontal granular cortex and behavior. New York: McGraw-Hill, 1964.

TEUBER, H. L. The riddle of frontal lobe function in man. In J. M. Warren \& K. Akert (Eds.), The frontal granular cortex and behavior. New York: McGraw-Hill, 1964.

WERNER, H., \& WAPNER, S. The Innsbruck studies on distorted visual fields in relation to an organismic theory of perception. Psych. Rev., 1955, 62, 130-138.

\section{Note}

1. The author is indebted to his colleagues, H. E. Rosvold, M. Mishkin and J. Semmes for their many helpful discussions and criticisms. 